\title{
The codevelopment of coastal fisheries monitoring methods to support local management
}

\author{
$\underline{\text { Eva Schemmel }}^{1,2}$, Alan M. Friedlander $^{3,4}$, Pelika Andrade $^{5,6,7}$, Ku ulei Keakealani $^{8}$, Linda M. Castro $^{9}$, Chad Wiggins $^{10}$, Bart A. $^{\text {. }}$ \\ $\underline{\text { Wilcox }}^{8}$, Yumi Yasutake ${ }^{11}$ and $\underline{\text { John } N}^{\text {. Kittinger }}{ }^{12}$
}

\begin{abstract}
Small-scale fisheries across the globe provide critical food security, livelihoods, and human well-being, but are threatened by a combination of local and global stressors, including overexploitation, pollution, and climate change. Participatory approaches to management, especially those that incorporate local communities and customary knowledge can provide meaningful biological information that supports sustainable fisheries management and builds local adaptive capacity to changing ocean conditions. Through a collaboration between fishers, scientists, NGOs, and regulating agencies, we developed a low-cost, low-tech method to assess the seasonal spawning peaks, lunar spawning cycles, and size at maturity $\left(\mathrm{L}_{50}\right)$ for key targeted reef fish, combining traditional knowledge and practice with modern scientific approaches, including gonadosomatic index (GSI) and histology. Two years of community-based monitoring resulted in data from 57 species and 15 families of reef and nearshore fishes $(\mathrm{n}=2595)$, with detailed information for 10 species at 4 locations across the Hawaiian Islands. Comparisons between community-collected GSI data and scientifically (histologically) assessed spawning cycles and size at reproductive maturity produced similar results suggesting that these approaches can be applied in data-poor fisheries to assess spawning seasons and size at maturity $\left(\mathrm{L}_{50}\right)$, both of which are critical needs for effective fisheries management. Semistructured surveys revealed a large body of local knowledge on spawning times and harvest practices based on allowing spawning to occur before harvesting and protecting small and large size classes, but little evidence that fishers understand temporal patterns of spawning. This suggests that monitoring methods that fill key gaps such as this and are congruent with these local knowledge systems and customary harvest practices may be key for local stewardship and adaptive management.
\end{abstract}

Key Words: adaptive management; comanagement; customary ecological knowledge; fisheries

\section{INTRODUCTION}

Historically fisheries throughout the Pacific were managed through local and customary knowledge (Ruddle and Johannes 1990, Kittinger et al. 2015). In Hawai'i, customary fisheries management was highly localized, with practices that were specific to each district (moku), and even watershed (ahupua'a; McGregor 2007, Tissot et al. 2009, Jokiel et al. 2011). Lunar rhythms and seasonal patterns of important resources species were carefully monitored and used to develop moon calendars to inform wise management of these resources (Poepoe et al. 2007, Jokiel et al. 2011). Moon calendars predicted seasonal, monthly, and daily ecological cycles of harvested species, and this information was used to dictate proper (pono) harvest seasons and strategies and identify kapu or no-take periods during critical periods of development and reproduction of these species (Titcomb 1972, Poepoe et al. 2007). This knowledge came from an intimate connection of the practitioners to the resource and intergenerational knowledge transmission (Poepoe et al. 2007), as has been observed in other customary management systems (Berkes et al. 2000, McMillen et al. 2014).

Coincident with the erosion of customary marine tenure, fisheries catches in Hawai'i have declined dramatically because of increased human population, habitat destruction, overly efficient fishing techniques, and the loss of customary conservation practices (Smith 1993, Friedlander et al. 2004, Kittinger et al. 2011, McClenachan and Kittinger 2012), raising concerns about the sustainability of these stocks (Friedlander and DeMartini
2002, Williams et al. 2008, Nadon et al. 2015). Social and environmental changes in Hawaii $i$ and across the Asia-Pacific region have led to efforts by communities to revitalize customary knowledge and seek increased stewardship and management of their resources (Minerbi 1999, Ayers and Kittinger 2014).

In Hawai $i$, interest in collaborative management has resulted in several institutional changes, including a process to designate community-based subsistence fisheries management areas (CBSFAs), a specific marine management designation that was passed into law in 1994 by the Hawai ${ }^{i}$ State Legislature (Kittinger et al. 2012, Ayers and Kittinger 2014). This designation allows communities to strengthen their local influence and accountability for the health and sustainability of their resources through the establishment of locally appropriate fishery harvest rules in spatially designated marine management areas (Kittinger et al. 2012, Friedlander et al. 2013, Ayers and Kittinger 2014). Although legislation for comanagement now exists in Hawai $i$, progress toward establishing community-managed marine areas has been slow (Kittinger et al. 2012, Ayers and Kittinger 2014).

One of the major challenges hindering comanagement in Hawai $\mathrm{i}$ is a lack of monitoring information on resource condition and species biology that state management institutions require to establish management regulations. A solution for gathering local resource information needed to understand and manage local resources is to combine customary knowledge and practices with contemporary scientific approaches (Ruddle et al. 1992, Aswani and Hamilton 2004, Moller et al. 2004). Customary knowledge

${ }^{1}$ Fisheries Ecology Research Lab, University of Hawai'i, Manoa, ${ }^{2}$ Conservation International, Honolulu, Hawai'i, ${ }^{3}$ Pristine Seas, National Geographic Society, ${ }^{4}$ Fisheries Ecology Research Lab, Department of Biology, University of Hawai'i, ${ }^{5}$ Na Maka o Papahanaumokuakea, ${ }^{6}$ University of Hawai'i Hilo, ${ }^{7}$ Hawai'i Sea Grant, ${ }^{8}$ Hui Aloha Kîholo, ${ }^{9}$ Maui DLNR-Division of Aquatic Resources, ${ }^{10}$ The Nature Conservancy, Hawai'i Program, ${ }^{11}$ NOAA Papahanaumokuakea Marine National Monument, ${ }^{12}$ Conservation International, Center for Oceans, Honolulu, Hawai'i 
can provide observational information gathered over very long time periods and can be very detailed; however, these knowledge systems can lack the documentation and precise quantification that are often required in contemporary management systems (Moller et al. 2004). Combining knowledge sources greatly increases capacity for gathering information needed for management at a local or community scale (Moller et al. 2004, Olsson et al. 2004, Silvano and Valbo-Jørgensen 2008). The success of this approach has been previously demonstrated and significant improvements in resource management have been made by implementing local resource monitoring that incorporates local and customary knowledge with scientific assessments (Moller et al. 2004, Danielsen et al. 2005, 2007, Thornton and Scheer 2012). A collaborative approach that includes local resource monitoring of fish biology, including spawning seasons and size at maturity is particularly relevant for fisheries comanagement. This information is currently lacking for most species, and is further complicated by high spatial heterogeneity in reproductive characteristics (Williams et al. 2006, Taylor 2014; E. Schemmel and A. M. Friedlander, unpublished manuscript). However, this information is essential for setting fishery harvest control regulations such as size limits and closed seasons, which is utilized in both customary (Poepoe et al. 2007, Friedlander 2015) and contemporary fisheries management (Haddon 2010).

We describe a participatory approach to fisheries monitoring and conservation developed to support collaborative marine resource management in Hawai $i$. This research was conducted through a collaborative project between Hawaiian communities, research scientists, local nongovernmental organizations (NGOs), and government regulatory agencies. The objectives of this work were to develop methods for local fisheries monitoring programs that incorporate cultural practices with scientific assessments that can be performed by participating fishers. We describe how we integrated cultural practices and scientific assessments of fish reproduction, to assess size at maturity along with seasonal and lunar spawning cycles for important resource species. The purpose of developing these methods is to further enhance the capacity of communities to protect spawning populations in accordance with customary practices, and ensure the food security, livelihood benefits, and cultural practices associated with these small-scale coastal fisheries. By training and empowering local communities to monitor their resources and by building partnerships with regulatory agencies, we were able to break down barriers to communication and fill data gaps, which have until now, led to inadequate management and poor compliance with fisheries regulations.

\section{MATERIALS AND METHODS}

\section{Study locations}

Research was conducted at four sites in the main Hawaiian Islands: Maunalua Bay (O'ahu), North Kona (Hawai'i), West Maui, and North Kaua'i (Fig. 1). These locations differed in the diversity of users, urban development, and human population density. The majority of the monitoring was done by the following participating community groups: Mâlama Maunalua (Oahu), Hui Aloha Kîholo (North Kona), Ka upulehu Marine Life Advisory Committee (Hawai i), and Polanui Hui (West Maui). The monitoring methods were piloted in several additional communities including: Kailapa (Hawaiii), Wailuku (Maui), Hana (Maui), Kahana (O'ahu), Hâ'ena (Kaua'i), and Hanalei (Kauai; Fig 1). All of these community groups are part of a large network organized with the support of Kua'âina Ulu 'Auamo, a community-based initiative for protecting, restoring, and caring for Hawaii (http://kuahawaii.org/). Additionally, numerous fishers that were not connected to any of these communities, but who also fished in these areas, participated in monitoring by sending in information directly to the Fisheries Ecology Research Lab (FERL) at the University of Hawai'i. Monitoring data used in our analyses were collected from January 2013 through January 2015.

Fig. 1. Participating community locations for the development of the monitoring methods in the main Hawaiian Islands. Boxed regions indicate areas where the majority of the monitoring data was collected.

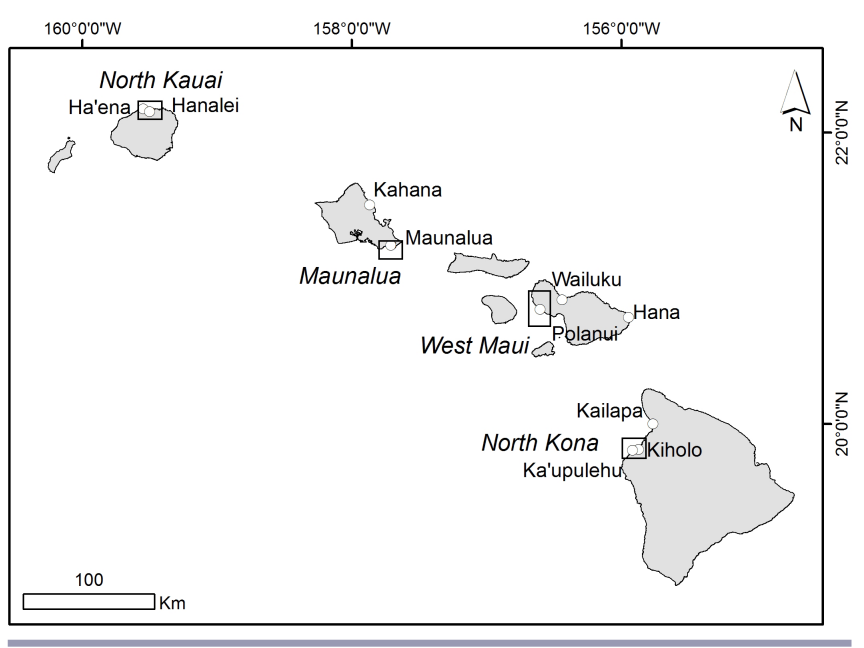

\section{Monitoring tools}

To facilitate gathering information on fish biology, we worked with communities to develop fishing (lawai'a) logbooks. These logbooks were designed as a yearly calendar, broken down by month, and moon phase (Fig. 2). Customary Hawaiian moon phase designations (anahulu) were used, which divide the lunar cycle into three 10-day periods: ho'onui (waxing - first quarter), poepoe (full), and emi (waning - last quarter). Logbooks provided space to record local observations that were used along with the biological information to develop moon calendars that are used to share knowledge on seasonal cycles in resources, particularly peak spawning times, as was the customary practice in ancient Hawai i.

We used a field microscope that allowed us to better assess the spawning condition of reef and nearshore fishes. This microscope was inexpensive and constructed of locally available materials (cost $\sim \$ 10)$ that used a smart phone or basic camera to take photos of the viewing field (Fig. 2). It was constructed of plywood, Plexiglass, and used a magnifying lens from an inexpensive laser pointer (http://www.instructables.com/id/10Smartphone-to-digital-microscope-conversion/). Additionally, this low cost technology was used to educate communities and participating fishers on how to identify spawning times based on oocyte (egg) development. 
Fig. 2. Monitoring tools for community-based spawning season assessments. (A) Field microscope that works with smart phones or standard cameras. Built from Plexiglas and plywood for viewing fish oocytes (developing eggs; instructions for construction are available at http://www.instructables.com/ id/10-Smartphone-to-digital-microscope-conversion). (B) An example of a photo from the field microscope showing hydrated kūmū (Parupeneus porphyreus) oocytes. (C) and (D) Lawai'a logbook (fishing logbook) used to record monthly and lunar patterns in spawning of harvested nearshore fishes.

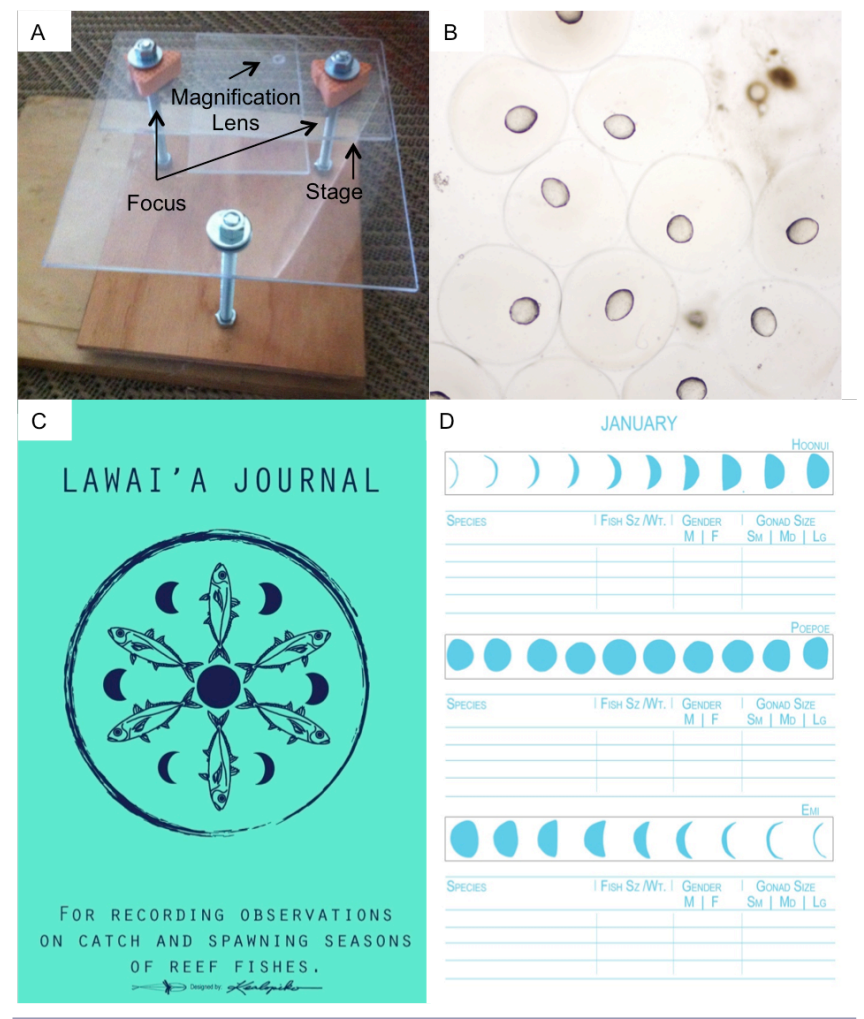

\section{Community monitoring}

Within each participating community, respected and active fishers volunteered to be fishery monitors. The role of the fishery monitors was to organize other fishers in the community to share information on fish spawning seasons and collect gonad samples from priority species for scientific analysis. We held workshops to train participating fishers and fishery monitors on standardized methods of measuring, weighing, assessing gender, and collecting gonad samples from harvested species (Fig. 3). At these training sessions the lawai' $a$ logbooks were distributed and used to demonstrate sampling and recording procedures. The tools used to monitor spawning seasons and reproductive biology included the following: measuring tapes, fish scales (Rapala RMDS-25 25 $\mathrm{lb} / 11.4 \mathrm{~kg}$, by $0.1 \mathrm{~kg}$ ), gonad scales (SWS100 $100 \mathrm{~g}$ by $0.01 \mathrm{~g}$ ), lawai a logbooks, and fishery monitor data sheets. Additionally, the field microscope was used to look for hydrated oocytes (oocytes undergoing final maturation), as indications of spawning from the collected gonad samples.
Fig. 3. Endemic Hawaiian flagtail (Aholehole, Kuhlia xenura) with enlarged male gonad caught from Maunalua Bay March 2014 (fork length $=21 \mathrm{~cm}$ ).

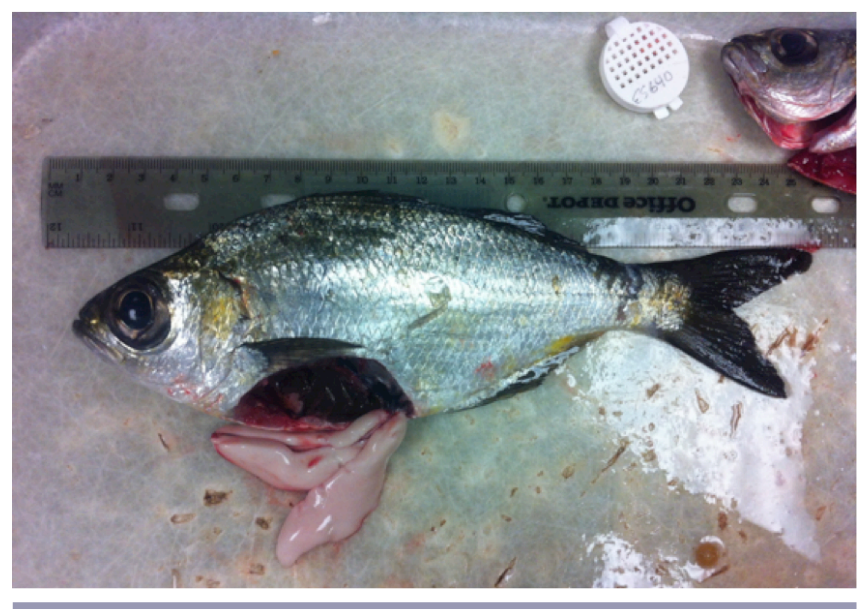

The community monitoring methods were used to examine a variety of commonly harvested reef fishes, with the species of interest differing among locations and dictated by resource availability and the community's harvest preferences (Table 1). Monitoring information was collected through lawai a logbooks, yearly meetings, workshops, and data from fishery monitors.

\section{Gonadosomatic index}

To increase local capacity to monitor spawning seasons, we trained communities and fishery monitors on how to analyze fish spawning seasons based on the gonadosomatic index (GSI), which is the relative percent mass of the fish gonad divided by the gonad-free mass of the fish (GSI = gonad mass/gonad-free fish mass*100). Gonad weight, and therefore GSI, increases during peak spawning periods (Claramunt et al. 2003). The GSI is lower in immature or undeveloped fishes, thus allowing for an estimate of the size at which fish become reproductively active and are capable of spawning.

\section{Biological analyses}

\section{Gonad preparation}

Fish gonad samples were collected throughout the year by fishery monitors. Gonad samples were fixed in $10 \%$ phosphate buffered formaldehyde for a minimum of $48 \mathrm{hrs}$ before being rinsed overnight in fresh water, drained, and shipped overnight via refrigerated air cargo to the University of Hawai'i at Mânoa on O'ahu for histological assessment.

\section{Size at maturity and spawning season assessments}

We combined all information from fishers' logbooks, community monitoring, and gonad samples to determine local life history characteristics for important harvested reef fishes in each community. Comparisons between community-gathered GSI and histological assessments were conducted for female Acanthurus triostegus sandvicensis (convict tang, manini in Hawaiian) and female Ctenochaetus strigosus (goldeye surgeonfish, kole in Hawaiian), two of the most commonly harvested reef fishes in these communities during the study, to test the accuracy of 
Table 1. The Hawaiian, common, and scientific names of the top 10 monitored species along with the corresponding sample size, size range, and mean size (fork length). ${ }^{\dagger}=$ endemic species or subspecies.

\begin{tabular}{|c|c|c|c|c|c|c|}
\hline Hawaiian & Common & Scientific & $\mathrm{n}$ & Min & $\operatorname{Max}$ & Mean $\pm \mathrm{sd}$ \\
\hline$\overline{\text { Aholehole }}$ & Hawaiian flagtail & Kuhlia xenura & 313 & 10.7 & 27.0 & $17.8 \pm 2.7$ \\
\hline Akule & Bigeye scad & Selar crumenophthalmus & 38 & 24.5 & 28.8 & $26.1 \pm 0.9$ \\
\hline Ama'ama & Striped mullet & Mugil cephalus & 114 & 31.8 & 57.0 & $41 \pm 6.2$ \\
\hline Aweoweo & Bigeye & Priacanthus meeki & 36 & 12.7 & 28.0 & $20.5 \pm 3.4$ \\
\hline Kala & Bluespine unicornfish & Naso unicornis & 34 & 21.9 & 50.0 & $37.9 \pm 6.3$ \\
\hline $\mathrm{Kole}^{\dagger}$ & Gold-eye surgeonfish & Ctenochaetus strigosus & 298 & 7.6 & 20.6 & $14.5 \pm 2.2$ \\
\hline$K \overline{\mathrm{u}} m \overline{\mathrm{u}}^{\dagger}$ & White saddle goatfish & Parupeneus porphyreus & 19 & 20.5 & 33.0 & $25.5 \pm 4.5$ \\
\hline Manini $i^{\dagger}$ & Convict tang & Acanthurus triostegus sandvicensis & 1174 & 8.3 & 24.0 & $16.5 \pm 2.2$ \\
\hline 'U'u & Bigscale soldierfish & Myripristis berndti & 36 & 14.0 & 24.0 & $18.6 \pm 2.2$ \\
\hline 'U'u & Pearly soldierfish & Myripristis kuntee & 23 & 14.0 & 20.0 & $16.9 \pm 1.6$ \\
\hline
\end{tabular}

community monitoring in assessing female size at maturity and spawning seasons. C. strigosus and A. triostegus sandvicensis are Hawaiian endemic species and subspecies, respectively.

Standardized histological assessments of reproductive state were done for all gonad samples. We choose to focus on female reproductive biology because we found it to be a more reliable indicator of spawning timing because of relatively large increases in gonad weights caused by the hydration of oocytes as spawning nears (West 1990). Female histological classification of size at maturity was performed using standardized ovarian development classifications (Wallace and Selman 1981), with reproductive maturity assigned to individuals with vitellogenic oocytes, post ovulatory oocytes, or hydrated eggs, because these are signs of spawning activity. Size at maturity was assessed using GSI by classifying maturity using $5,10,15$, and $20 \%$ of the maximum GSI as cutoffs for maturity (Fontoura et al. 2009). GSI and histological assessment of size at maturity $\left(\mathrm{L}_{50}\right)$ were determined as the size at which $50 \%$ of individuals were mature for a given fork length (FL: length of the fish from the tip of the snout to the fork or middle of the tail) or age (Lowerre-Barbieri et al. 2009). To calculate $\mathrm{L}_{50}$, FL was regressed against the proportion of mature individuals using the glm function in $\mathrm{R}$ using the binomial family and a logit link function (Development Core Team R 2013). $\mathrm{L}_{50}$ estimates calculated from 5, 10, 15, and $20 \%$ of maximum GSI were compared to the histologically derived $\mathrm{L}_{50}$ and calculated as the percent difference from the histological assessment.

Histologically assigned reproductive state was used to calculate the spawning fraction (proportion of spawning fish per day) based on the presence of hydrated oocytes (DeMartini and Fountain 1981). We choose to use hydrated oocytes instead of the postovulatory follicles (Hunter and Macewicz 1985) because hydrated oocytes are more reliably identified using the field microscopes. Therefore, spawning fraction was easily understood by community participants and could also be assessed by communities themselves using the field microscope or similar tools. Monthly mean spawning fraction was derived to determine the peak spawning times for harvested fishes. Spawning fraction was compared with average monthly GSI values from histologically assessed mature females to determine the feasibility of using GSI to estimate spawning seasons. Mean daily spawning fraction was also calculated to determine the moon phases of peak spawning, when monitoring data were available at this temporal scale, and compared to daily mean GSI values.

\section{Cultural process and local knowledge}

An important step toward the development of community-based fishery monitoring programs is to understand the needs of the community and place. This allows for monitoring to focus where it most needed, and therefore most effective, and is a critical step in the process because community values, priorities, and perceptions of threats differ by location. We used principles of transparency, common goals, and shared responsibility to build relationships and foster the environment that allowed for a strong collaboration to occur (Yochum et al. 2011). Community input was sought throughout the entire process, including the identification of priority fishery species, local knowledge of spawning seasons, and community fishing practices.

Promoting sustainable harvest practices among all resource users is strongly encouraged by communities throughout Hawai i. Local sustainable fishing strategies range from detailed practices based on biology and behaviors of targeted fish species to social mores that promote care and respect for the environment. For many community participants these practices are a code of conduct (Poepoe et al. 2007) or cultural norms (Vaughan et al 2016) that dictate a respectful and necessary way of interacting with their environment.

The sharing of these practices and local knowledge is often done through the revitalized practice of developing moon calendars (Friedlander et al. 2002, Poepoe et al. 2007). Moon calendars incorporate local knowledge and provide baseline information on natural cycles and processes. We used the development of moon calendars to capture local observations and reflections on customary practices. The moon calendars also utilized information on lunar and seasonal spawning that was collected in the lawai' $a$ logbooks. These calendars thus become tools to share the code of conduct and additional sustainable fishing practices, including spawning seasons and size at first reproduction. The printed moon calendars that were created from local and customary knowledge and scientific monitoring also provided communities a resource that they used to approach and communicate community values and harvesting practices among a diverse set of resource users, including various types of fishers, e.g., subsistence, recreational, and commercial, and nonconsumptive users, e.g., boaters, surfers, divers, swimmers, etc.

Local ecological knowledge was also incorporated through structured and semistructured surveys, as well as participation of researchers in cultural and local activities (for methods review see 
Bunce et al. 2000). Structured surveys were also conducted to gather information on fishing practices and local knowledge of spawning cycles from fishers outside of the participating communities. Questions included the number of years of fishing experience, the number of fishing days per year, target species, spawning seasons for harvested fishes, and sustainable practices (see Appendix 1). A total of 81 nearshore fishers from across the Hawaiian Islands participated in structured surveys.

\section{Data sharing}

Monitoring information was used to generate reports on the local spawning seasons for harvested reef fishes and was disseminated to the communities and participating fishers in the form of formal reports and Hawaiian moon calendars. These calendars were developed within communities to share fish spawning season information along with cultural practices and values. Community input was sought during all phases of the project from the development of the process and data collection to analyses and reporting.

\section{RESULTS}

\section{Community monitoring}

Through the support and diligent efforts of local communities, we were able to gather fishery and biological information at each monitoring location. Two years of community-based monitoring resulted in data from 15 families and 57 species of reef and nearshore fishes $(n=2595)$, with detailed information for 10 species (Table 1). Through the monitoring program, spawning seasons were documented for several harvested fishes based on the presence of hydrated oocytes and relatively higher GSI (Table 2). All monitored fishes were pelagic spawners, having hydrated oocytes with a translucent oocyte and one or more yolk globules present. The morphology and size of hydrated oocytes made them easily distinguished for all of the species examined, using field microscopes and confirmed through histological examination. Monitoring information was then used to create spawning guides that were incorporated into local moon calendars along with local knowledge and community fishing practices, which were the basis for establishing local sustainable fishing practices.

\section{Biological assessments}

Many of the monitored reef fishes showed similar peaks in spawning, with the most species spawning in spring, generally March through June (Table 2). Peak spawning seasons for species that were monitored in more than one location (manini [Acanthurus triostegus sandvicensis] and kole [Ctenochaetus strigosus]) showed overlap in their months of spawning between locations with extended spawning seasons occurring in Maunalua Bay (Oahu).

Size at maturity: comparing GSI and histologically assessed $L_{50}$ We compared the estimated size at maturity using histological and GSI data for female manini collected at two of our monitoring locations (Maunalua Bay and North Kona). Size at maturity for female manini based on GSI was larger than that estimated based on histology (Table 3, Fig. 4). The 5\% of the maximum GSI cutoffs for assigning maturity was found to be the most similar to the histological assessment compared with the 10\%, 15\%, and $20 \%$ of the maximum GSI cutoffs for assigning maturity for manini, and was within 5.5 to $12.4 \%$ of the histological assessment (Fig. 4).
Table 2. Spawning seasons for several harvested fish species from North Kona (Hawai i), West Maui (Maui), and Maunalua Bay (Oahu) from January 2013 to January 2015. Some spawning was found to occur outside peak spawning seasons and annual variability was also found to occur. These spawning seasons are guidelines for which to compare temporal changes in spawning cycles at each location. See Table 1 for species common and scientific names.

\begin{tabular}{|c|c|c|c|c|c|c|c|c|c|c|c|}
\hline \multicolumn{12}{|l|}{ Location } \\
\hline North Kona & & & & & & & & & & & \\
\hline Kole & & & $\mathrm{X}$ & $\mathrm{X}$ & $\mathrm{X}$ & $\mathrm{X}$ & & & & & \\
\hline Manini & & & & $\mathrm{X}$ & $\mathrm{X}$ & $\mathrm{X}$ & $\mathrm{X}$ & $\mathrm{X}$ & $\mathrm{X}$ & & \\
\hline West Maui & & & & & & & & & & & \\
\hline $\begin{array}{c}\text { Akule } \\
\text { Maunalua }\end{array}$ & & & & $\mathrm{X}$ & $\mathrm{X}$ & $\mathrm{X}$ & & & & & \\
\hline Aholehole & $\mathrm{X}$ & $\mathrm{X}$ & $\mathrm{X}$ & $\mathrm{X}$ & $\mathrm{X}$ & $\mathrm{X}$ & & & & $\mathrm{X}$ & $\mathrm{X}$ \\
\hline Aweoweo & & & $\mathrm{X}$ & $\mathrm{X}$ & $\mathrm{X}$ & $\mathrm{X}$ & $\mathrm{X}$ & $\mathrm{X}$ & & & \\
\hline Kole & & & $\mathrm{X}$ & $\mathrm{X}$ & $\mathrm{X}$ & $\mathrm{X}$ & $\mathrm{X}$ & $\mathrm{X}$ & & & \\
\hline$K \bar{u} m \bar{u}$ & & $\mathrm{X}$ & $\mathrm{X}$ & & & & & & & & \\
\hline Manini & $\mathrm{X}$ & $\mathrm{X}$ & $\mathrm{X}$ & $\mathrm{X}$ & $\mathrm{X}$ & $\mathrm{X}$ & $\mathrm{X}$ & $\mathrm{X}$ & $\mathrm{X}$ & $\mathrm{X}$ & $\mathrm{X}$ \\
\hline
\end{tabular}

Table 3. Results from 5, 10, 15, and $20 \%$ of maximum gonadosomatic index (GSI) used to assess size at maturity for manini (convict tang, Acanthurus triostegus sandvicensis) from Maunalua Bay (Oahu) and North Kona (Hawaiii). Histological size at maturity for each location is bolded and compared to each GSI percentage cutoff to assess differences between GSI and histologically assessed size at maturity $\left(\mathrm{L}_{50}\right)$.

\begin{tabular}{lccc}
\hline \hline Location & $\begin{array}{c}\text { GSI Cut Off } \\
(\% \text { of max GSI })\end{array}$ & $\mathrm{L}_{50}(\mathrm{~cm})$ & Difference (\%) \\
\hline Maunalua & - & $\mathbf{1 2 . 7}$ & - \\
& 5 & 14.6 & 12.4 \\
& 10 & 15.3 & 16.7 \\
North Kona & 15 & 16.6 & 24.7 \\
& 20 & 16.6 & 24.7 \\
& - & $\mathbf{1 5 . 6}$ & - \\
& 5 & 16.5 & 5.5 \\
& 10 & 16.9 & 8.5 \\
& 15 & 17.1 & 9.7 \\
& 20 & 17.6 & 12.7 \\
\hline
\end{tabular}

Comparing GSI and histologically assessed spawning seasons Histological and GSI methods resulted in similar spawning seasons assessments. Community-collected GSI data were a good indicator of spawning seasons. Female monthly GSI and histologically assessed spawning fraction tracked each other and produced a nearly identical assessment of spawning season for manini and kole from Maunalua Bay in 2013 (Figs. 5 and 6). Furthermore, the assessment of the lunar spawning cycle of female manini for Maunalua Bay was similar for both methods, with peaks in spawning activity occurring during new and full moons (Fig. 5). The peak spawning in August 2013 was around the blue moon, the second full moon in one calendar month. 
Fig. 4. Comparing gonadosomatic index (GSI) to histological assessment of size at maturity for manini (convict tang, Acanthurus triostegus sandvicensis) from North Kona (A and C) and Maunalua Bay (B and D). Individual fish GSI values are plotted in the top panels for North Kona (A) and Maunalua Bay (C). Bottom panels display the size at maturity assessments. Dashed lines indicate the size at which $50 \%$ of the population is capable of spawning $\left(\mathrm{L}_{50}\right)$ based on each method. The histologically assessed size at maturity is in red. The black line represents the 5\% maximum GSI assessed maturity, the gray lines are the 10,15 , and $20 \%$ maturity assessments moving from left to right.
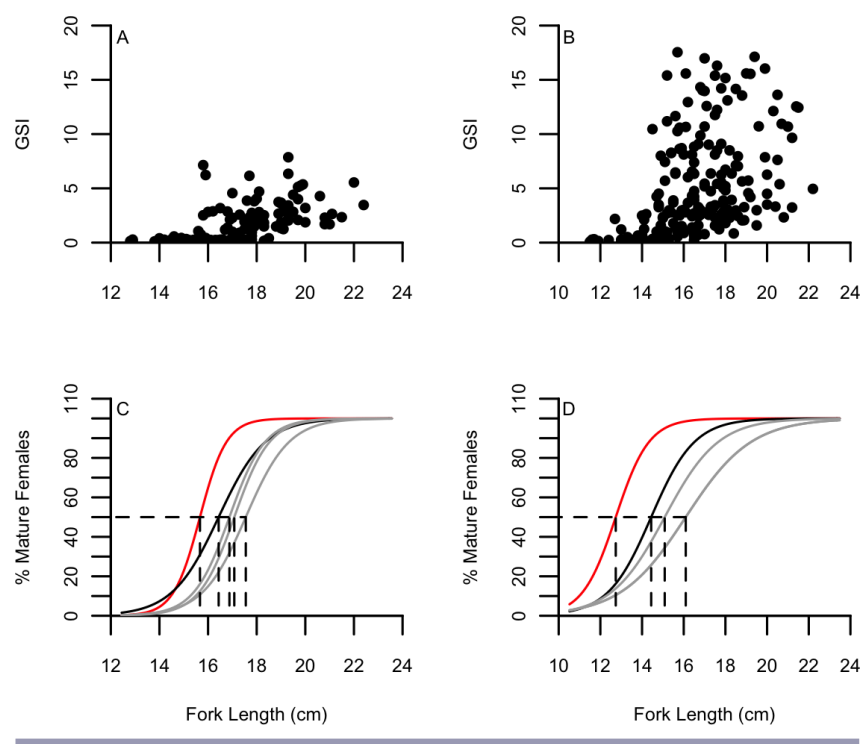

Local knowledge and community fishing practices

Surveys and participant observations were successful in gathering detailed knowledge on natural cycles and sustainable fishing practices. Participants averaged 22 years $( \pm 14$ yrs sd) of fishing experience and reported to fish, on average, 76 days per year $( \pm 91$ days sd). Fishers used three primary gear types, with $27.5 \%$ reporting the use of pole and line, $13.8 \%$ spear, and $3.7 \%$ lay gillnet. Many fishers used multiple types of gear, with $41.3 \%$ reporting using pole and line and spear, and 13.7\% using a combination of pole and line, spear, and throw-net (for description of types of gear see Titcomb 1972).

Fishers were asked to provide spawning season information for fish species that they commonly harvested. Responses varied widely, with no clear consensus on peak spawning periods for the majority of species harvested. Despite this lack of consensus, surveys revealed respondents were aware of spawning and seasonal cycles in resource fishes. A total of $57 \%$ of fishers reported they examine their catch for eggs or milt to determine if spawning is occurring, and $46.2 \%$ observed other seasonal cycles in fishery resources (e.g., movements and migrations, aggregations, recruitment). However, $<10 \%$ of the fishers that observed seasonal cycles keep track or recorded this information. In summary, most fishers check their catch to see if the species they harvested are spawning, but very few track spawning patterns over time.
Fig. 5. Comparison of gonadosomatic index (GSI) and spawning fraction to determine timing of spawning in manini (convict tang, Acanthurus triostegus sandvicensis). (A) Monthly mean GSI and spawning fraction to assess the spawning season for manini from Maunalua Bay in 2013. Dashed line represents GSI. (B) Daily mean GSI and spawning fraction to assess the lunar spawning pattern for manini from Maunalua Bay. Moon phase (new (black circle) and full (open circle)) are illustrated on top of figure. Dashed line represents GSI and spawning fraction is represented by a solid black line.
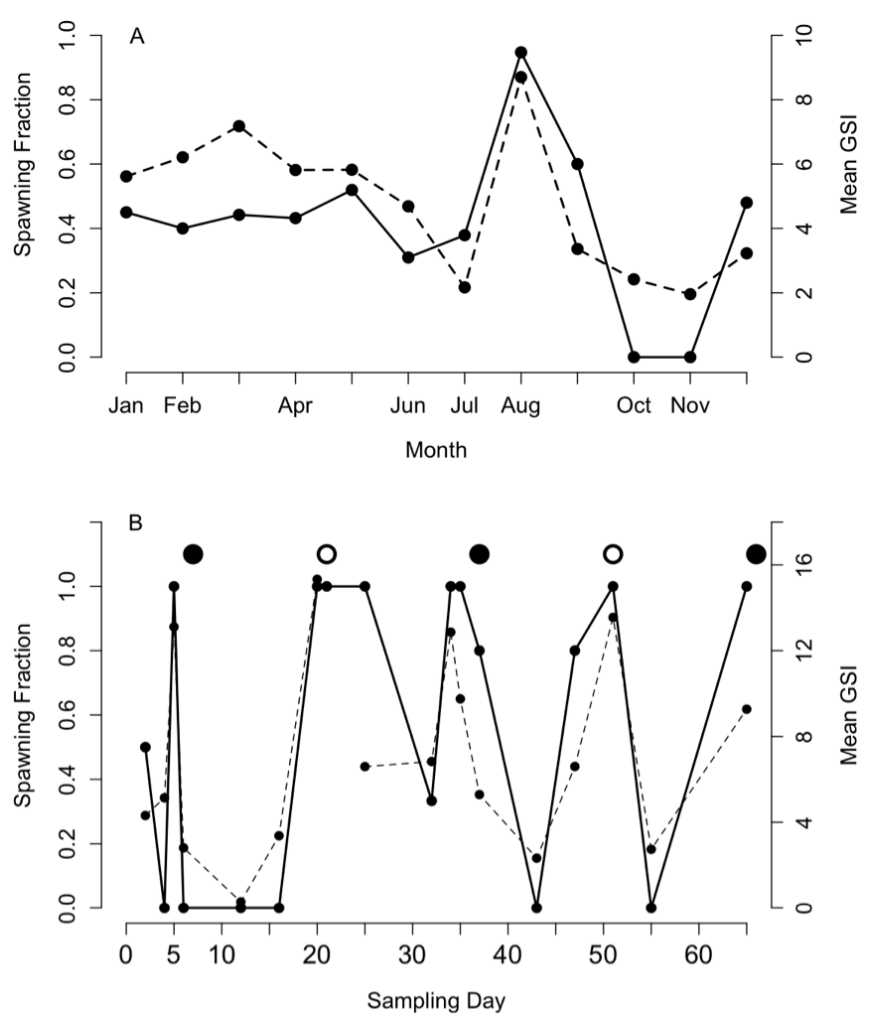

Fig. 6. Comparison of gonadosomatic index (GSI) and spawning fraction to determine spawn timing in kole (goldeye surgeonfish, Ctenochaetus strigosus) through monthly mean GSI and spawning fraction to assess the spawning season for kole from Maunalua Bay in 2013. Dashed line represents GSI and spawning fraction is represented by a solid black line.

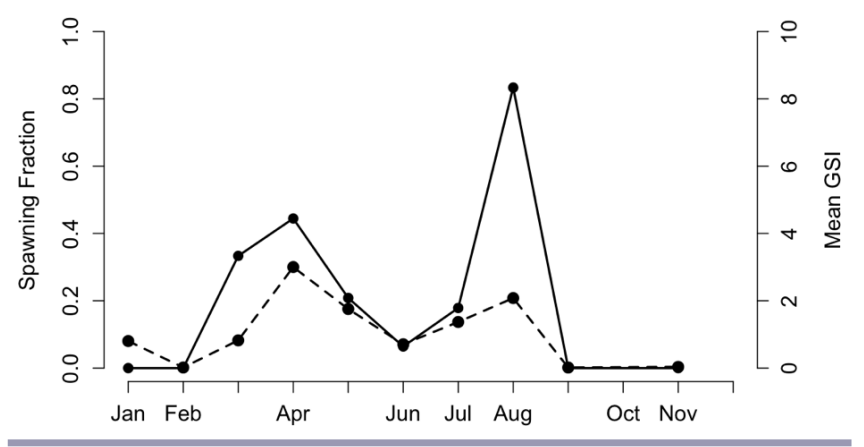


Table 4. Top reported pono (sustainable) practices from fisher surveys with intended purpose and benefit to resource management.

\begin{tabular}{|c|c|c|}
\hline Pono Practice & Purpose & $\begin{array}{c}\text { Percent of } \\
\text { Respondents }\end{array}$ \\
\hline Take only what you need. & Limits total catch and leaves resources in the environment. & $36 \%(n=29)$ \\
\hline Harvest appropriate size. & $\begin{array}{l}\text { Avoids catching undersized, immature fish and leaves larger fish that release } \\
\text { more eggs and spawn more often. }\end{array}$ & $24 \%(n=19)$ \\
\hline Catch fish according to season. & Reduces catch of spawning fish and other critical life history stages. & $14 \%(n=11)$ \\
\hline Pick up trash, clean, and nurture your harvest area. & Habitat restoration and maintenance. & $11 \%(n=9)$ \\
\hline $\begin{array}{l}\text { Use the right fishing gear and remove nets, hooks, } \\
\text { and old fishing gear from the reefs. }\end{array}$ & Reduce bycatch and reduce habitat destruction. & $6 \%(n=5)$ \\
\hline Rotate grounds. & Let areas rest and recover from fishing. & $4 \%(n=3)$ \\
\hline Observe, learn, and teach the youth. & $\begin{array}{l}\text { Increased understanding of the resource leads to development of sustainable } \\
\text { harvest practices and teaching the youth transmits this knowledge. }\end{array}$ & $4 \%(n=3)$ \\
\hline
\end{tabular}

Results from the survey on sustainable fishing practices revealed a common code of conduct that was evidenced by consistency in responses. These practices included: limiting catch, protecting spawning fish as well as small and large size classes, protection of habitat, local monitoring, and education and knowledge transmission (Table 4). Further detailed knowledge of resources was evident through observer participation and semistructured surveys. For example, one fisher responded during a survey: "To know the resource we must go consistently and think about the entire system (ecosystem)." This response likely reveals the holistic way of thinking that stems from customary knowledge. Semistructured surveys also revealed a large body of local knowledge on spawning times and harvest practices based on allowing spawning to occur before harvesting. For example, fishers described the harvest practice for bigeye scad (Selar crumenophthalmus, akule in Hawaiian) as allowing the fish the opportunity to spawn prior to harvest. "Akule enter the bay, but fishing does not occur at this time. They then disappear as they go down to the bottom to spawn. Once they reappear, their color has changed [from silver] to brown and this is the time we go harvest."

Many of these sustainable fishing practices based on customary knowledge coincided with our monitoring goals of understanding spawning seasons and size at maturity. The practices were then linked with results from our biological monitoring to develop suggested no-take times or kapu seasons within the moon calendar. Size at maturity from our monitoring was also included in the moon calendars as the suggested minimum harvest size to ensure that individuals had a chance to spawn at least once before being harvested.

\section{DISCUSSION}

By using a collaborative approach, we were successful in developing local fishery monitoring methods that yielded valuable, reliable data on fisheries species spawning times, achieved by combining traditional approaches together with modern scientific methods. In particular, gonadosomatic index (GSI) can be used by fishers and communities to determine spawning seasons and estimate size at maturity $\left(\mathrm{L}_{50}\right)$, which are critical to developing harvest control rules such as closed seasons (kapu), fish size limits, and gear regulations. Using this monitoring information, sustainable fishing practices already in place (protecting spawning fish and small and large size classes) were reinforced and new practices were developed including recording gonad and fish weights to monitoring spawning seasons. By paying attention to the spawning cycles of harvested fishes, fishers adjusted their times of harvest to avoid catching fishes during spawning seasons. Our research shows the importance of local fishery monitoring for providing information that reflects local values (codes of conduct and local fishing practices) and natural cycles in resources for use in local stewardship and fisheries comanagement. Ultimately, the benefit of collaborative fishery monitoring programs like this one is their ability to build local capacity to adaptively manage resources.

\section{Community-based methods for assessing spawning cycles and size} at maturity

The collaborative community fisheries monitoring program yielded results that were as effective as conventional scientific assessments to accurately determine spawning seasons, but with substantially lower costs and the added benefit of fisher engagement. Identification of spawning seasons is of great importance for local management (Sadovy De Mitcheson and Erisman 2012) and was culturally very important for traditional management (Titcomb 1972, Poepoe et al. 2007). Fishers were very engaged in the monitoring of spawning seasons and developed spawning season assessments for several harvested reef fishes. We showed that, by using basic measurement tools (scales, measuring tapes, and field microscopes) and simple GSI analysis, communities can develop and implement a standard monitoring method for determining spawning seasons. Comparisons of GSI and histological methods produced similar results for assessing female spawning seasons and lunar spawning patterns. The ease and low cost of GSI methods means that fishers can monitor the spawning season and lunar spawning patterns for all species of interest. Scientific advice throughout the process is recommended but histology assessments may play more of a supporting role and may only be necessary to confirm reproductive gender and spawning status when needed.

Spawning season assessments were strengthened by using a simple tool, a low-cost field microscope. Using these microscopes, communities were able to validate GSI estimates of spawning timing through the identification of hydrated oocytes, while also providing hands-on learning opportunities. Field microscopes are excellent tools for assessing spawning individuals and can also be used to correctly classify individuals with hydrated oocytes as mature. Hydrated oocytes have been shown to have a high probability of correct classification of spawning and also the classification of mature individuals (Murua et al. 2003). 
Community-gathered GSI data were also valuable for estimating size at maturity. Although we found that female GSI generally overestimates size at maturity, locally derived GSI data used to estimate size of maturity were closer to the local size of maturity estimates than the State of Hawai'i's minimum size limits (http:// dlnr.hawaii.gov/dar/fishing/fishing-regulations/marine-fishes-andvertebrates). The state's size at maturity estimates are derived from the best available data, however this data may come from scientific studies that are a snap shot in space or time, and often from other locations outside of Hawai'i. In particular the discrepancies may be caused by the variability in size at maturity $\left(\mathrm{L}_{50}\right)$ across locations throughout Hawai'i, or an average of male and female size at maturity estimates that have been shown to vary by gender (E. Schemmel and A. M. Friedlander, unpublished manuscript).

We choose to focus our monitoring results on female spawning seasons and size at maturity. This is in part because female ovaries increase in size and weight as spawning nears and the egg stages such as hydration can be monitored. For most reef fishes, the spawning seasons and size at maturity of males can be determined by applying pressure to the abdomen and checking for the release of milt, indicating that the fish is mature and capable of spawning. Males are often capable of spawning throughout the month and outside the female spawning season, therefore they are not the best indicator of spawning timing.

Additional considerations are needed when assessing the reproductive biology of hermaphroditic fishes (those capable of changing sex). For hermaphroditic fishes, GSI methods would still allow for the identification of spawning seasons and female size at maturity, however additional information is necessary such as size at sex change. To determine size at sex change additional scientific support may be needed to accurately assess gender, which can be complicated by the presence of transitional individuals (individuals with gonads are undergoing gender reallocation, i.e., have both female and male tissues.

These methods are successful when combined with a careful sampling design. A well-developed sampling design prior to monitoring, where samples are collected across multiple time frames, e.g., daily, monthly, and annually, is needed to answer questions about spawning seasons and spawning frequency, e.g., lunar or daily spawning patterns. Additionally, including multiple gear types and sampling from multiple habitats during monitoring is important because this increases the probability of sampling the entire population and provides a more accurate picture of the fish's reproductive biology (Kuparinen et al. 2009; E. Schemmel and A. M. Friedlander, unpublished manuscript). Understanding possible sampling biases and including as many fishers as possible into the monitoring program helps to interpret monitoring results and reduce erroneous conclusions that may be caused by differences in sampling caused by different gear types or habitats.

Box 1: Spawning season and size at maturity must be assessed together

Information on spawning seasons and size at maturity are interdependent. For example, if a large proportion of the catch was reproductively immature, the low gonad weights from these individuals would reduce the monthly GSI value and potentially mask any spawning season activity. Therefore, it is important to obtain an estimate of size at maturity to be used in spawning season monitoring and analyses. Conversely, it is important to know the spawning season to collect accurate information on size at maturity. This is due to low GSI across all size ranges outside of spawning seasons. This complexity can be resolved through monthly sampling throughout the year to estimate the spawning seasons, and then assessing size at maturity from samples collected during the spawning season. Similarly, once size at maturity is known, removing immature sized fish from the spawning season assessment improves the accuracy in identifying spawning seasons.

\section{Informing local management}

We were able to share key life history and fishery information needed to revise fishery regulations such as size limits and closed seasons within the state regulating agency, the Hawai i Division of Aquatic Resources. Additionally, we demonstrated that community-gathered information on spawning seasons and target harvest sizes can help fulfill the monitoring criteria for proposed regulations in comanaged fishery areas. We describe how specific management measures can be established from the information gathered through these monitoring programs.

Understanding the optimal sizes to target in the fishery is important for maintaining population sustainability. Setting minimum size limits based on size at maturity is a critical part of fishery management because it allows fishes to reach maturity before being harvested (Heppell et al. 2005, Haddon 2010). Here we focused on assessing the size at maturity, or the minimum size limit, however, focusing fishers' efforts toward larger size classes can also be a problem because these larger sized fish produce more eggs and spawn more frequently than smaller sized fishes (Clarke 1987, Berkeley et al. 2004, Claramunt et al. 2007, Evans et al. 2008). For example, a $20-\mathrm{cm}$ manini has been shown to produce 4-fold more eggs than a 16-cm individual, and spawn twice as often (E. Schemmel and A. M. Friedlander, unpublished manuscript). The importance of leaving the big fish is well known (for review see Birkeland and Dayton 2005) and understanding the size classes that contribute the most to reproduction may be more important than knowing the size at maturity for setting size limits (Vaughan and Carmichael 2002, Heppell et al. 2005, Hixon et al. 2014). Scientific advice and histological assessments can complement community GSI data by helping to assess the fecundity (number of eggs spawned) and spawning frequency (how often spawning occurs). Together, this information can inform optimal target sizes for fishery management tools such as slot limits.

Seasonal and lunar spawning cycles are critical information for setting closed seasons and for protecting spawning aggregations either through temporal or spatial closures (Beets and Friedlander 1999, Heppell et al. 2005, Sadovy and Domeier 2005). Information on peak spawning times, both seasonal and lunar, can be used to set closed areas or habitats and species-specific fishery seasonal closures. Seasonal closures are effective fishery management regulations for fish species that have short, distinct, and well-known spawning seasons, thus limiting fishing for a few months out of the year to allow spawning to be uninterrupted. Our results suggest that this may be an effective strategy for soldierfishes (Myripristis species, ' $u$ ' $u$ in Hawaiian) and the 
endemic white saddle goatfish (Parupeneus porphyreus, kûmû in Hawaiian). Fish species that have prolonged spawning seasons, but still aggregate at known moon phases within the lunar month, for example, manini, can be regulated with short lunar closures or area closures at known spawning sites. Such closures have a historical basis in traditional practices for coastal fisheries; for example, in precontact Hawai'i, resource managers often placed a customary kapu (no-take) ban on harvesting for species (Friedlander et al. 2013).

Annual monitoring is also needed because of changes in spawning driven by environmental changes, including climate change. For example, in August 2013 there was a peak in spawning for both manini and kole. Because both fishes spawn in relation to the moon, we attribute this peak to the second full moon that occurred in the month of August (a "blue moon"). This peak was not observed in our spawning season assessments for manini or kole in 2014. It is expected that further changes in spawn timing and other natural cycles will vary in response to environmental fluctuations and ongoing climate change (McMillen et al. 2014).

Although these monitoring methods were useful in this context, it is very important to communicate that monitoring spawning seasons and size at maturity are among many fishery management approaches. It is by no means a cure-all solution to fisheries management. We argue that it is necessary to keep an open mind to varied management approaches because there are many sustainable fishery management approaches outside contemporary fisheries management norms (McClanahan et al. 2006, Cinner and Aswani 2007). For example, in Hawai'i, customary harvest practices were based on cycles of abundance and occurrence, which dictated harvest, including the harvest of juveniles (Titcomb 1972, Poepoe et al. 2007), which is contradictory to our suggestion of harvesting above the size of maturity. There are also many additional sustainable practices to consider that included temporal, spatial, gear, and effort restrictions that are regulated by cultural and spiritual practices and taboos (Johannes 1978, McClanahan et al. 1997, Colding and Folke 2001, Cinner and Aswani 2007).

\section{Developing local capacity for stewardship}

Through community participation, development of moon calendars, and surveys we learned that although many experienced nearshore fishers in Hawai' $i$ are aware of the natural cycles of their resources, including spawning seasons, few of fishers record this information. In addition, because of the diversity of resource users, documentation is needed to share and communicate the resource information that dictates local practices and resource management. To facilitate recording this information we developed the lawai' $a$ logbook (available online for download at http://spawningseasons.com/\#intro) to record fisheries catch along with spawning season information. These personal logs act as journals with information on monthly and lunar spawning, thus providing fishers with the tools to keep track of the spawning cycle of harvested fishes and can be used to inform harvest times.

Moon calendars were found to be another tool to build local resource management capacity. Moon calendars provide the structure for learning and adapting to natural cycles in local resources and are one way to revitalize traditional tenure (Poepoe et al. 2007, Gombos et al. 2013, McMillen et al. 2014; Kalei
Nu'uhiwa http://www.kaleinuuhiwa.com). We show that moon calendars can also provide the framework for combining local knowledge and scientific monitoring for improving our understanding of local fisheries. Furthermore, disseminating these moon calendars promotes communication of local cultural and fishery practices to the larger and diverse community resource users.

Participatory monitoring, such as described here, ensures that the necessary management information will be accessible not only to managers, but also to resource users. Ultimately, participatory monitoring allows harvest decisions to be revised based on direct observations. Similarly, customary knowledge was based on direct observations of resources and natural cycles, which have been shown to result in adaptive management, (Berkes et al. 2000, Wilson et al. 2006, Mahon et al. 2008), in other words, "learning by doing" (Walters and Holling 1990). Furthermore, incorporating fishers into the monitoring and management process encourages responsibility for the resources and develops community-based values for acceptable harvest practices that are enforced and regulated by users themselves (Prince 2003, Wiber et al. 2004, Cinner et al. 2009, Basurto and Ostrom 2009, Bergseth et al. 2015).

\section{CONCLUSIONS}

This project demonstrates the benefits of collaborative resource monitoring and local participatory approaches to support fisheries comanagement to sustain food subsistence and cultural security of resource dependent communities. Benefits from this project included increased understanding by fishers of natural cycles in resources, which led to behavioral changes in fishing practices, and an increased understanding by state regulating agencies of the need for local management and revised regulations. Community monitoring can provide the information needed for fisheries assessments and allow for solutions on the time scale needed for effective management and conservation action. Last, participatory monitoring programs like this one allow for relationships to develop among fishers, scientists, and regulatory agencies, which builds trust among groups, increases management capacity, and ultimately leads to more resilient linked social-ecological systems.

Responses to this article can be read online at: http://www.ecologyandsociety.org/issues/responses. $\mathrm{php} / 8818$

\footnotetext{
Acknowledgments:

We acknowledge all of the involved fishers and community members and those that led the revitalization of Hawaiian Moon Calendars, in particular Uncle Mac Poepoe, Kalei Nu'uhiwa, and the Hanalei Watershed Hui. Community support and guidance was provided by Hui Aloha Kīholo, Polanui Hui, Wailuku Community Managed Makai Area, Kailapa Community Association, and Hā'ena and Hana community members. Many collaborations were formed and relationships built with the help of Matt Ramsey, NOAA Fisheries Extension Agent. Special thanks to Lauren Mathews and Kanani Frazer for their assistance in the design of the moon calendars.
} 
Funding and support was provided by Conservation International Hawa'i and NOAA coral Reef Conservation Program award to the State of Hawai i Department of Land \& Natural Resources, Division of Aquatic Resources Award Number NA13NOS4820014. Conservation International staff that worked diligently along with us on this research includes Luka Mossman and Kehau Springer. Support was also provided by The Nature Conservancy of Hawai'i. Finally, support and guidance from the Fisheries Ecology Research Lab at the University of Hawai'i at Mānoa members: Mary Donovan, Alex Filous, Jonatha Giddens, Whitney Goodell, Ily Iglesias, Haruko Muro-Koike, Keith Kamikawa, Kaylyn McCoy, Kosta Stamoulis, and Paolo Usseglio. We would also like to thank Keoki Stender for his contribution of marine life photos to the moon calendars. Approval of University of Hawai'i Animal Care and Use Committee was through protocol \#13-1710 and formal exemption approval for gonad samples donated by fishermen. Use of human studies in this research was approved through IRB exemption \#22394.

\section{LITERATURE CITED}

Aswani, S., and R. J. Hamilton. 2004. Integrating indigenous ecological knowledge and customary sea tenure with marine and social science for conservation of bumphead parrotfish (Bolbometopon muricatum) in the Roviana Lagoon, Solomon Islands. Environmental Conservation 31(1):69-83. http://dx.doi. org/10.1017/s037689290400116x

Ayers, A. L., and J. N. Kittinger. 2014. Emergence of comanagement governance for Hawai'i coral reef fisheries. Global Environmental Change 28:251-262. http://dx.doi.org/10.1016/j. gloenvcha.2014.07.006

Basurto, X., and E. Ostrom. 2009. The core challenges of moving beyond Garrett Hardin. Journal of Natural Resources Policy Research 1(3):255-259. http://dx.doi.org/10.1080/19390450903040447

Beets, J., and A. Friedlander. 1999. Evaluation of a conservation strategy: a spawning aggregation closure for red hind, Epinephelus guttatus, in the U.S. Virgin Islands. Environmental Biology of Fishes 55(1):91-98. http://dx.doi.org/10.1023/A:1007404421518

Bergseth, B. J., G. R. Russ, and J. E. Cinner. 2015. Measuring and monitoring compliance in no-take marine reserves. Fish and Fisheries 16(2):240-258. http://dx.doi.org/10.1111/faf.12051

Berkeley, S. A., M. A. Hixon, R. J. Larson, and M. S. Love. 2004. Fisheries sustainability via protection of age structure and spatial distribution of fish populations. Fisheries 29:23-32. http://dx.doi. org/10.1577/1548-8446(2004)29[23:FSVPOA]2.0.CO;2

Berkes, F., J. Colding, and C. Folke. 2000. Rediscovery of traditional ecological knowledge as adaptive management. Ecological Applications 10(5):1251-1262. http://dx.doi. org/10.1890/1051-0761(2000)010[1251:roteka]2.0.co;2

Birkeland, C., and P. K. Dayton. 2005. The importance in fishery management of leaving the big ones. Trends in Ecology \& Evolution 20(7):356-358. http://dx.doi.org/10.1016/j.tree.2005.03.015

Bunce, L., P. Townsley, R. Romeroy, and R. Pollnac. 2000. Socioeconomic manual for coral reef management. Global Coral Reef Monitoring Network, Townsville, Australia.
Cinner, J. E., and S. Aswani. 2007. Integrating customary management into marine conservation. Biological Conservation 140(3-4):201-216. http://dx.doi.org/10.1016/j.biocon.2007.08.008

Cinner, J. E., T. R. McClanahan, T. M. Daw, N. A. J. Graham, J. Maina, S. K. Wilson, and T. P. Hughes. 2009. Linking social and ecological systems to sustain coral reef fisheries. Current Biology 19(3):206-212. http://dx.doi.org/10.1016/j.cub.2008.11.055

Claramunt, G., R. Roa, and L. Cubillos. 2003. Estimating daily spawning fraction using the gonadosomatic index: application to three stocks of small pelagic fish from Chile. Pages 43-49 in O. S. Kjesbu, J. R. Hunter, and P. R. Witthames, editors. Modern approaches to assess maturity and fecundity of warm-and coldwater fish and squids. Norwegian Institute of Marine Research, Bergen, Norway.

Claramunt, G., R. Serra, L. R. Castro, and L. Cubillos. 2007. Is the spawning frequency dependent on female size? Empirical evidence in Sardinops sagax and Engraulis ringens off northern Chile. Fisheries Research 85(3):248-257. http://dx.doi.org/10.1016/ j.fishres.2007.01.009

Clarke, T. A. 1987. Fecundity and spawning frequency of the Hawaiian anchovy or nehu, Encrasicholina purpurea. Fishery Bulletin 85(1):127-138.

Colding, J., and C. Folke. 2001. Social taboos: "invisible" systems of local resource management and biological conservation. Ecological Applications 11(2):584-600.

Danielsen, F., N. D. Burgess, and A. Balmford. 2005. Monitoring matters: examining the potential of locally-based approaches. Biodiversity \& Conservation 14(11):2507-2542. http://dx.doi. org/10.1007/s10531-005-8375-0

Danielsen, F., M. M. Mendoza, A. Tagtag, P. A. Alviola, D. S. Balete, A. E. Jensen, M. Enghoff, and M. K. Poulsen. 2007. Increasing conservation management action by involving local people in natural resource monitoring. AMBIO 36(7):566-570. http://dx.doi.org/10.1579/0044-7447(2007)36[566:icmabi]2.0.co;2

DeMartini, E. E., and R. K. Fountain. 1981. Ovarian cycling frequency and batch fecundity in the queenfish, Seriphus politus: attributes representative of serial spawning fishes. Fishery Bulletin 79(3):547-560.

Development Core Team R. 2013. R: a language and environment for statistical computing. R Foundation for Statistical Computing, Vienna Austria.

Evans, R. D., G. R. Russ, and J. P. Kritzer. 2008. Batch fecundity of Lutjanus carponotatus (Lutjanidae) and implications of notake marine reserves on the Great Barrier Reef, Australia. Coral Reefs 27(1):179-189. http://dx.doi.org/10.1007/s00338-007-0309-8

Fontoura, N. F., A. S. Braun, and P. C. C. Milani. 2009. Estimating size at first maturity $\left(\mathrm{L}_{50}\right)$ from Gonadossomatic Index (GSI) data. Neotropical Ichthyology 7(2):217-222. http://dx.doi. org/10.1590/S1679-62252009000200013

Friedlander, A. M. 2015. A perspective on the management of coral reef fisheries. Pages 208-214 in C. Mora, editor. Ecology of fishes on coral reefs. Cambridge University Press, Cambridge, UK. http://dx.doi.org/10.1017/cbo9781316105412.023 
Friedlander, A. M., and E. E. DeMartini. 2002. Contrasts in density, size, and biomass of reef fishes between the northwestern and the main Hawaiian islands: the effects of fishing down apex predators. Marine Ecology Progress Series 230:253-264. http://dx. doi.org/10.3354/meps230253

Friedlander, A. M., J. Nowlis, and H. Koike. 2004. Stock assessments using reference points and historical data: stock status and catch limits. Pages 91-118 in J. Kittinger, L. McClenachan, K. Gedan, and L. Blight, editors. Applying marine historical ecology to conservation and management: using the past to manage for the future. University of California Press, Berkeley, California, USA.

Friedlander, A., K. Poepoe, K. Poepoe, K. Helm, P. Bartram, J. Maragos, and I. Abbott. 2002. Application of Hawaiian traditions to community-based fishery management. Proceedings of the Ninth International Coral Reef Symposium, Bali, 23-27 October 2000 2:813-815.

Friedlander, A. M., J. M. Shackeroff, and J. N. Kittinger. 2013. Customary marine resource knowledge and use in contemporary Hawai'i. Pacific Science 67(3):441-460. http://dx.doi.org/10.2984/67.3.10

Gombos, M., S. Atkinson, and S. Wongbusarakum. 2013. Adapting to a changing climate: guide to local early action planning (LEAP) and management planning. Micronesia Conservation Trust, Pohnpei, Federal States of Micronesia.

Haddon, M. 2010. Modelling and quantitative methods in fisheries. CRC, Boca Raton, Florida, USA.

Heppell, S. S., S. A Heppell, A. J. Read, and L. B. Crowder. 2005. Effects of fishing on long-lived marine organisms. Pages 211-231 in E. A. Norse and L. B. Crowder, editors. Marine conservation biology: the science of maintaining the sea's biodiversity. Island, Washington, D.C., USA.

Hixon, M. A., D. W. Johnson, and S. M. Sogard. 2014. BOFFFFs: on the importance of conserving old-growth age structure in fishery populations. ICES Journal of Marine Science 71 (8):2171-2185. http://dx.doi.org/10.1093/icesjms/fst200

Hunter, J. R., and B. J. Macewicz. 1985. Measurement of spawning frequency in multiple spawning fishes. Technical Report NMFS:79-94. National Oceanic and Atmospheric Administration, Washington, D.C., USA.

Johannes, R. E. 1978. Reproductive strategies of coastal marine fishes in the tropics. Environmental Biology of Fishes 3(1):65-84. http://dx.doi.org/10.1007/bf00006309

Jokiel, P. L., K. S. Rodgers, W. J. Walsh, D. A. Polhemus, and T. A. Wilhelm. 2011. Marine resource management in the Hawaiian archipelago the traditional Hawaiian system in relation to the Western approach. Journal of Marine Biology 2011:1-16. http:// dx.doi.org/10.1155/2011/151682

Kittinger, J. N., A. Ayers, and E. E. Prahler. 2012. Policy briefing. Co-management of coastal fisheries in Hawai'i: overview and prospects for implementation. [online] URL: https://ssrn.com/ abstract $=2590207$

Kittinger, J. N., J. E. Cinner, S. Aswani, and A. T. White. 2015. Back to the future: integrating customary practices and institutions into comanagement of small-scale fisheries. Pages 135-161 in J. N. Kittinger, L. McClenachan, K. B. Gedan, L. K. Blight, editors. Marine historical ecology in conservation: applying the past to manage for the future. University of California Press, Berkeley, California, USA. http://dx.doi.org/10.1525/ california/9780520276949.003.0007

Kittinger, J. N., J. M. Pandolfi, J. H. Blodgett, T. L. Hunt, H. Jiang, K. Maly, L. E. McClenachan, J. K. Schultz, and B. A. Wilcox. 2011. Historical reconstruction reveals recovery in Hawaiian coral reefs. PLoS ONE 6(10):e25460. http://dx.doi. org/10.1371/journal.pone.0025460

Kuparinen, A., S. Kuikka, and J. Merilä. 2009. Estimating fisheries-induced selection: traditional gear selectivity research meets fisheries-induced evolution. Evolutionary Applications 2 (2):234-243. http://dx.doi.org/10.1111/j.1752-4571.2009.00070.x

Lowerre-Barbieri, S. K., N. Henderson, J. Llopiz, S. Walters, J. Bickford, and R. Muller. 2009. Defining a spawning population (spotted seatrout Cynoscionnebulosus) over temporal, spatial, and demographic scales. Marine Ecology Progress Series 394:231-245. http://dx.doi.org/10.3354/meps08262

Mahon, R., P. McConney, and R. N. Roy. 2008. Governing fisheries as complex adaptive systems. Marine Policy 32 (1):104-112. http://dx.doi.org/10.1016/j.marpol.2007.04.011

McClanahan, T. R., H. Glaesel, J. Rubens, and R. Kiambo. 1997. The effects of traditional fisheries management on fisheries yields and the coral-reef ecosystems of southern Kenya. Environmental Conservation 24(2):105-120. http://dx.doi.org/10.1017/s0376892997000179

McClanahan, T. R., M. J. Marnane, J. E. Cinner, and W. E. Kiene. 2006. A comparison of marine protected areas and alternative approaches to coral reef management. Current Biology 16:1408-1413. http://dx.doi.org/10.1016/j.cub.2006.05.062

McClenachan, L. E., and J. N. Kittinger. 2012. Multicentury trends and the sustainability of coral reef fisheries in Hawai'i and Florida. Fish and Fisheries 14:239-255. http://dx.doi.org/10.1111/ j.1467-2979.2012.00465.x

McGregor, D. 2007. Na kua'aina: living Hawaiian culture. University of Hawai'i Press, Honolulu, Hawai'i, USA.

McMillen, H. L., T. Ticktin, A. Friedlander, S. D. Jupiter, R. Thaman, J. Campbell, J. Veitayaki, T. Giambelluca, S. Nihmei, E. Rupeni, L. Apis-Overhoff, W. Aalbersberg, and D. F. Orcherton. 2014. Small islands, valuable insights: systems of customary resource use and resilience to climate change in the Pacific. Ecology and Society 19(4):44. http://dx.doi.org/10.5751/ es-06937-190444

Minerbi, L. 1999. Indigenous management models and protection of the ahupua'a. Social process in Hawai'i. Pages 208-225 in I. G. Aoude, editor. The ethnic studies story: politics and social movements in Hawai i. University of Hawai'i Press, Honolulu, Hawai i, USA.

Moller, H., F. Berkes, P. O. Lyver, and M. Kislalioglu. 2004. Combining science and traditional ecological knowledge: monitoring populations for co-management. Ecology and Society 9(3):2. [online] URL: http://www.ecologyandsociety.org/vol9/ iss $3 / \operatorname{art} 2 /$ 
Murua, H., G. Kraus, F. Saborido-Rey, P. R. Witthames, A. Thorsen, and S. Junquera. 2003. Procedures to estimate fecundity of marine fish species in relation to their reproductive strategy. Journal of Northwest Atlantic Fishery Science 33:33-54. http://dx. doi.org/10.2960/J.v33.a3

Nadon, M. O., J. S. Ault, I. D. Williams, S. G. Smith, and G. T. DiNardo. 2015. Length-based assessment of coral reef fish populations in the main and Northwestern Hawaiian Islands. PLoS ONE 10(8):e0133960. http://dx.doi.org/10.1371/journal. pone. 0133960

Olsson, P., C. Folke, and F. Berkes. 2004. Adaptive comanagement for building resilience in social-ecological systems. Environmental Management 34(1):75-90. http://dx.doi.org/10.1007/s00267-003-0101-7

Poepoe, K. K., P. K. Bartram, and A. M. Friedlander. 2007. The use of traditional Hawaiian knowledge in the contemporary management of marine resources. Pages 117-141 in N. Haggen, B. Neis, and I. G. Baird, editors. Fishers' knowledge in fisheries science and management. UNESCO, Paris, France.

Prince, J. D. 2003. The barefoot ecologist goes fishing. Fish and Fisheries 4(4):359-371. http://dx.doi.org/10.1046/j.1467-2979.2003.00134. $\underline{\mathrm{X}}$

Ruddle, K., E. Hviding, and R. E. Johannes. 1992. Marine resources management in the context of customary tenure. Marine Resource Economics 7(4):249-273. http://dx.doi. org/10.1086/mre.7.4.42629038

Ruddle, K., and R. E. Johannes. 1990. Traditional marine resource management in the Pacific basin: an anthology. UNESCO/ Regional Office for Science, Jakarta, Indonesia.

Sadovy, Y., and M. Domeier. 2005. Are aggregation-fisheries sustainable? Reef fish fisheries as a case study. Coral Reefs 24 (2):254-262. http://dx.doi.org/10.1007/s00338-005-0474-6

Sadovy de Mitcheson, Y., and B. Erisman. 2012. Fishery and biological implications of fishing spawning aggregations, and the social and economic importance of aggregating fishes. Pages 225-284 in Y. Sadovy de Mitcheson and P. L. Colin, editors. Reef fish spawning aggregations: biology, research and management. Springer Science+Business Media B.V., Dordrecht, The Netherlands. http://dx.doi.org/10.1007/978-94-007-1980-4_8

Silvano, R. A. M., and J. Valbo-Jørgensen. 2008. Beyond fishermen's tales: contributions of fishers' local ecological knowledge to fish ecology and fisheries management. Environment, Development and Sustainability 10(5):657-675. http://dx.doi.org/10.1007/s10668-008-9149-0

Smith, M. K. 1993. An ecological perspective on inshore fisheries in the main Hawaiian Islands. Marine Fisheries Review 55:34-49.

Taylor, B. M. 2014. Drivers of protogynous sex change differ across spatial scales. Proceedings of the Royal Society B: Biological Sciences 281(1775):20132423. http://dx.doi.org/10.1098/ $\underline{\text { rspb.2013.2423 }}$

Thornton, T. F., and A. M. Scheer. 2012. Collaborative engagement of local and traditional knowledge and science in marine environments: a review. Ecology and Society 17(3):8. http://dx.doi.org/10.5751/es-04714-170308
Tissot, B. N., W. J. Walsh, and M. A. Hixon. 2009. Hawaiian Islands marine ecosystem case study: ecosystem- and communitybased management in Hawaii. Coastal Management 37 (3-4):255-273. http://dx.doi.org/10.1080/08920750902851096

Titcomb, M. 1972. Native use of fish in Hawai'i. University of Hawai'i Press, Honolulu, Hawai'i, USA.

Vaughan, D. S., and J. T. Carmichael. 2002. Estimating improvement in spawning potential ratios for South Atlantic Red Drum through bag and size limit regulations. North American Journal of Fisheries Management 22(3):895-906. http://dx.doi. org/10.1577/1548-8675(2002)022<0895:eiispr>2.0.co;2

Vaughan, M. B., B. Thompson, and A. L. Ayers. 2016. Pâwehe Ke Kai a'o Hâ'ena: creating state law based on customary indigenous norms of coastal management. Society \& Natural Resources 30(1):31-46. http://dx.doi.org/10.1080/08941920.2016.1196406

Wallace, R. A., and K. Selman. 1981. Cellular and dynamic aspects of oocyte growth in teleosts. American Zoologist 21(2): 325-343. http://dx.doi.org/10.1093/icb/21.2.325

Walters, C. J., and C. S. Holling. 1990. Large-scale management experiments and learning by doing. Ecology 71(6):2060-2068.

West, G. 1990. Methods of assessing ovarian development in fishes: a review. Marine and Freshwater Research 41(2):199-222. http://dx.doi.org/10.1071/mf9900199

Wiber, M., F. Berkes, A. Charles, and J. Kearney. 2004. Participatory research supporting community-based fishery management. Marine Policy 28(6):459-468. http://dx.doi. org/10.1016/j.marpol.2003.10.020

Williams, A. J., C. R. Davies, B. D. Mapstone. 2006. Regional patterns in reproductive biology of Lethrinus miniatus on the Great Barrier Reef. Marine and Freshwater Research 57 (4):403-414. http://dx.doi.org/10.1071/mf05127

Williams, I. D., W. J. Walsh, R. E. Schroeder, A. M. Friedlander, B. L. Richards, and K. A. Stamoulis. 2008. Assessing the importance of fishing impacts on Hawaiian coral reef fish assemblages along regional-scale human population gradients. Environmental Conservation 35(03):261-272. http://dx.doi. org/10.1017/s0376892908004876

Wilson, D. C., J. Raakjær, and P. Degnbol. 2006. Local ecological knowledge and practical fisheries management in the tropics: a policy brief. Marine Policy 30(6):794-801. http://dx.doi. org/10.1016/j.marpol.2006.02.004

Yochum, N., R. M. Starr, and D. E. Wendt. 2011. Utilizing fishermen knowledge and expertise: keys to success for collaborative fisheries research. Fisheries 36(12):593-605. http:// dx.doi.org/10.1080/03632415.2011.633467 
Appendix 1: Fishing Survey

1. Where do you spend the most time fishing?

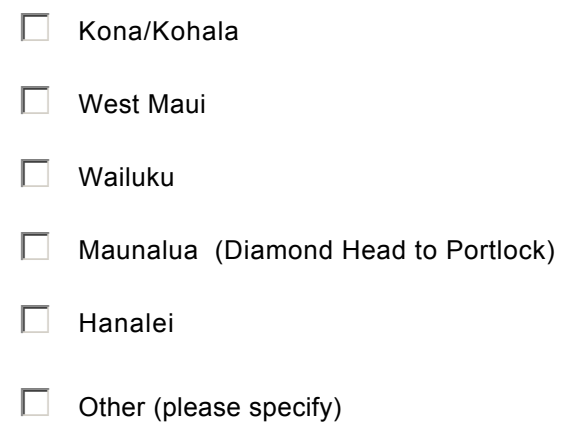

ГKona/Kohala

$\lceil$ West Maui

ए Wailuku

- Maunalua (Diamond Head to Portlock)

— Hanalei

○ Other (please specify)

2. Where did you grow up?

3. Number of years you have been fishing?

4. How many days do you spend fishing per year?

5. Who taught you how to fish (father, friend, uncle, yourself, etc.)? 


\section{Which fish do you mainly target?}

Г Aholehole/Flagtail

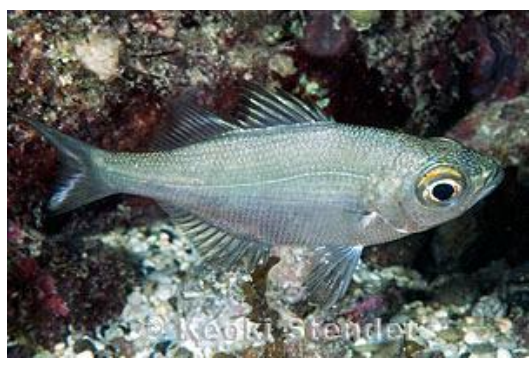

- Scad (Akule, Opelu)
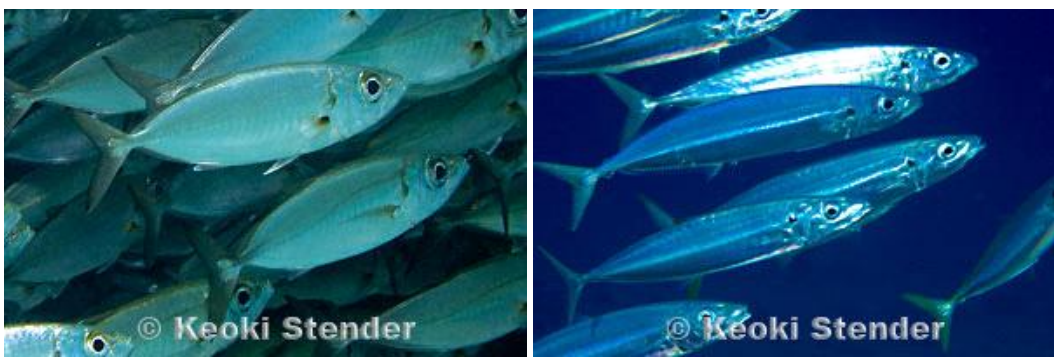

Г Unicornfish (Kala, Opelu Kala)

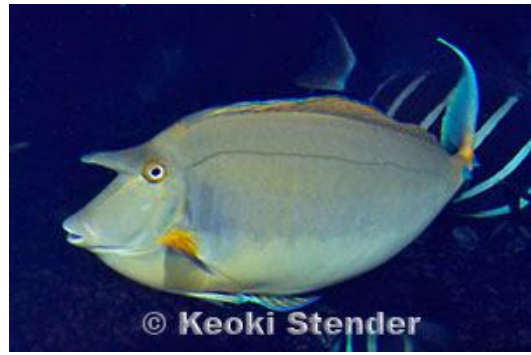

- Surgeonfish (Kole, Maikoiko, Palani, Pualu)
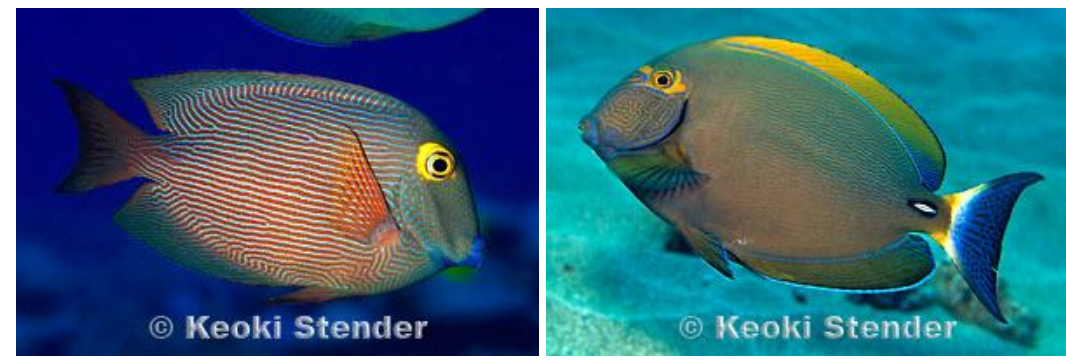

Г Other Surgeonfish (Manini)
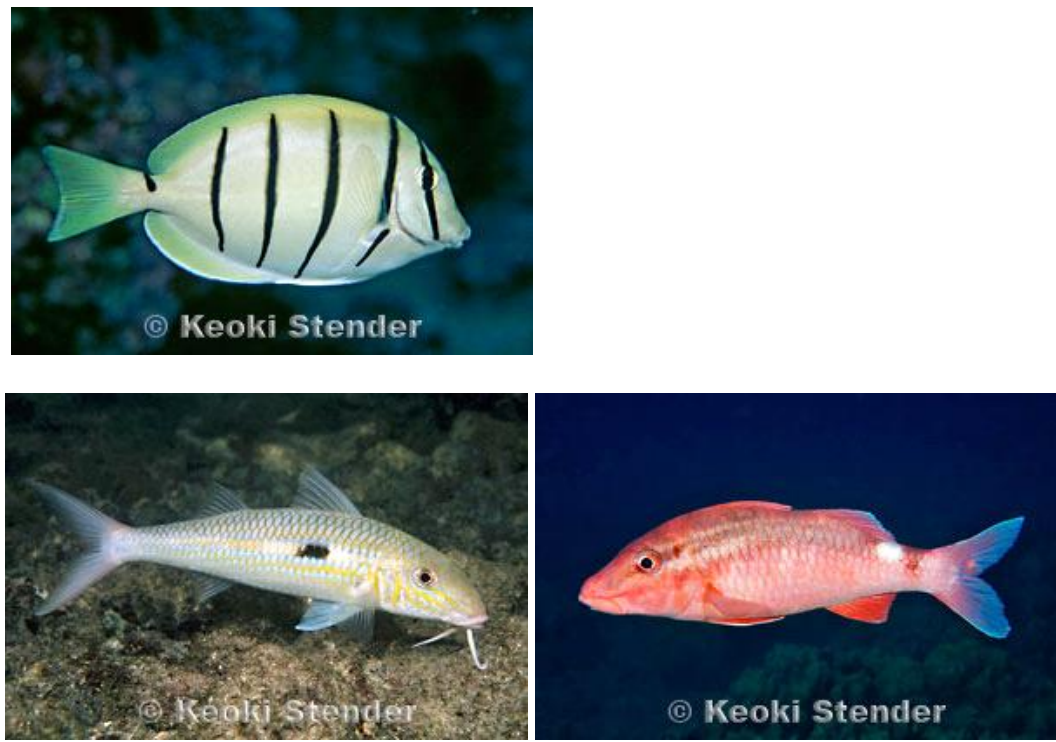

- Goatfish (Kumu, Moana, Weke)

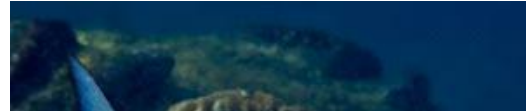


Г Nenue/Chub

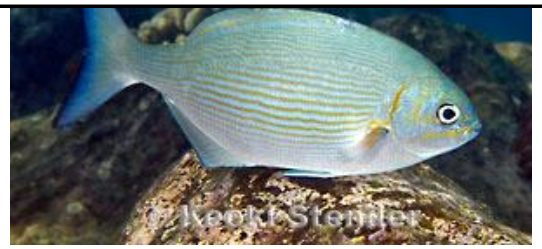

- Parrotfish (Uhu, Uhu uliuli, Uhu palukaluka)
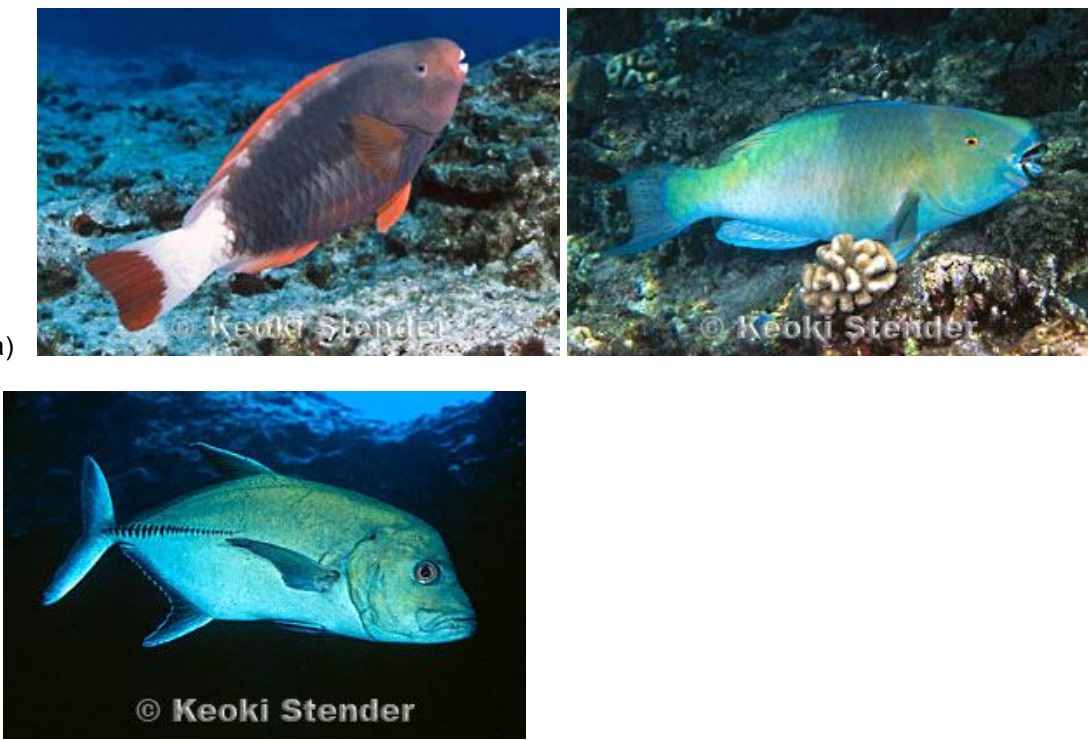

- Ulua/Jack
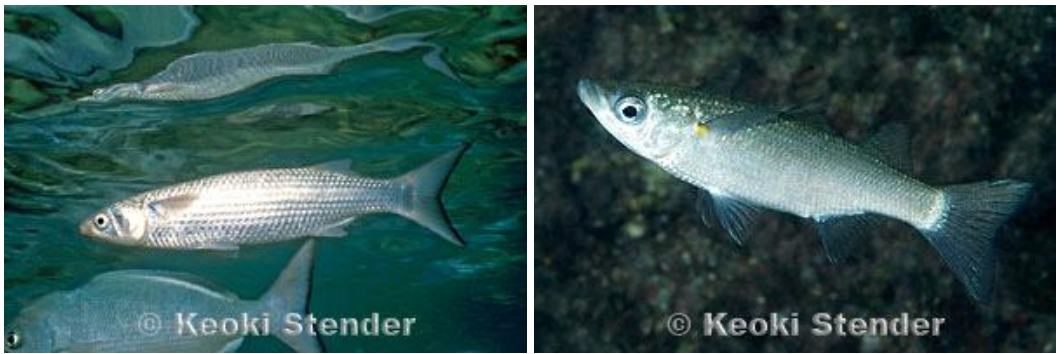

Mullet (Amaama, Uouoa)

7. What gear do you use to fish (pole, spear, throw net, laynet, other)?

8. Do you observe seasonal cycles in fishery resources?

O Yes

No

9. If you answered yes to Question 8, list the seasonal cycles you notice in your area:

10. Do you ever check your catch for milting or the presence of eggs (both are signs that spawing is taking place)?

Yes

No

11. If yes, who taught you to do this? 
12. Have you observed spawing or spawing behaviors? List fish and behaviors:

13. If you answered yes to Question 10 or 12 , do you record this information?

$\circ$ Yes

O No

14. If you answered yes to Question 13, how do you record this information?

15. Check the months that you believe spawning takes place:

\begin{tabular}{|c|c|c|c|c|c|c|c|c|c|c|c|c|}
\hline & Jan. & Feb. & Mar. & Apr. & May & Jun. & Jul. & Aug. & Sept. & Oct. & Nov. & Dec. \\
\hline Aholehole & \ulcorner & \ulcorner & $Г$ & Г & \ulcorner & \ulcorner & Г & $\Gamma$ & \ulcorner & Г & $\Gamma$ & $\Gamma$ \\
\hline Akule & \ulcorner & \ulcorner & \ulcorner & \ulcorner & \ulcorner & \ulcorner & \ulcorner & \ulcorner & \ulcorner & \ulcorner & \ulcorner & \ulcorner \\
\hline Ama ama & \ulcorner & \ulcorner & $\Gamma$ & $\Gamma$ & \ulcorner & \ulcorner & $\Gamma$ & $\Gamma$ & $\Gamma$ & $\Gamma$ & \ulcorner & $\Gamma$ \\
\hline Kala & \ulcorner & \ulcorner & \ulcorner & \ulcorner & \ulcorner & \ulcorner & \ulcorner & \ulcorner & \ulcorner & 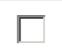 & \ulcorner & \ulcorner \\
\hline Kole & \ulcorner & \ulcorner & \ulcorner & \ulcorner & \ulcorner & $\Gamma$ & \ulcorner & $\Gamma$ & \ulcorner & \ulcorner & \ulcorner & $\Gamma$ \\
\hline Kumu & \ulcorner & \ulcorner & \ulcorner & \ulcorner & \ulcorner & \ulcorner & \ulcorner & \ulcorner & \ulcorner & \ulcorner & \ulcorner & \ulcorner \\
\hline Manini & $\Gamma$ & $\Gamma$ & $\Gamma$ & $\Gamma$ & \ulcorner & $\Gamma$ & \ulcorner & $\Gamma$ & \ulcorner & $\Gamma$ & $\Gamma$ & $\Gamma$ \\
\hline Moana & \ulcorner & \ulcorner & \ulcorner & \ulcorner & \ulcorner & \ulcorner & \ulcorner & $Г$ & \ulcorner & \ulcorner & \ulcorner & $\Gamma$ \\
\hline Maikoiko & \ulcorner & \ulcorner & $\Gamma$ & $\Gamma$ & \ulcorner & \ulcorner & $\Gamma$ & $\Gamma$ & $\Gamma$ & $\Gamma$ & \ulcorner & $\Gamma$ \\
\hline Nenue & \ulcorner & \ulcorner & \ulcorner & \ulcorner & \ulcorner & \ulcorner & \ulcorner & \ulcorner & \ulcorner & \ulcorner & \ulcorner & \ulcorner \\
\hline Opelu & $\Gamma$ & \ulcorner & $\Gamma$ & $\Gamma$ & \ulcorner & \ulcorner & $\Gamma$ & $\Gamma$ & \ulcorner & $\Gamma$ & $\Gamma$ & $\Gamma$ \\
\hline Opelu Kala & \ulcorner & \ulcorner & \ulcorner & \ulcorner & \ulcorner & \ulcorner & $\sqsubset$ & \ulcorner & \ulcorner & \ulcorner & \ulcorner & \ulcorner \\
\hline Palani & \ulcorner & \ulcorner & $\Gamma$ & \ulcorner & \ulcorner & \ulcorner & \ulcorner & $\Gamma$ & \ulcorner & $\Gamma$ & $\Gamma$ & $\Gamma$ \\
\hline Pualu & \ulcorner & \ulcorner & \ulcorner & \ulcorner & \ulcorner & \ulcorner & \ulcorner & \ulcorner & \ulcorner & \ulcorner & \ulcorner & \ulcorner \\
\hline Pualu Ringtail & \ulcorner & \ulcorner & \ulcorner & \ulcorner & \ulcorner & \ulcorner & \ulcorner & $\Gamma$ & \ulcorner & $\Gamma$ & \ulcorner & $\Gamma$ \\
\hline Uhu & \ulcorner & \ulcorner & $\Gamma$ & \ulcorner & \ulcorner & \ulcorner & \ulcorner & \ulcorner & \ulcorner & $\Gamma$ & \ulcorner & $\Gamma$ \\
\hline Unu Uliuli & \ulcorner & \ulcorner & \ulcorner & $\Gamma$ & \ulcorner & \ulcorner & $\Gamma$ & \ulcorner & \ulcorner & $\Gamma$ & \ulcorner & \ulcorner \\
\hline Uhu Palukaluka & \ulcorner & \ulcorner & \ulcorner & \ulcorner & \ulcorner & \ulcorner & \ulcorner & \ulcorner & \ulcorner & \ulcorner & \ulcorner & \ulcorner \\
\hline Ulua & \ulcorner & \ulcorner & $\Gamma$ & \ulcorner & \ulcorner & \ulcorner & $\Gamma$ & $\Gamma$ & \ulcorner & \ulcorner & \ulcorner & $\Gamma$ \\
\hline Uouoa & \ulcorner & \ulcorner & \ulcorner & \ulcorner & \ulcorner & \ulcorner & \ulcorner & \ulcorner & \ulcorner & $\Gamma$ & \ulcorner & \ulcorner \\
\hline Weke & \ulcorner & $\Gamma$ & \ulcorner & $\Gamma$ & \ulcorner & \ulcorner & \ulcorner & $\Gamma$ & \ulcorner & $\Gamma$ & $\Gamma$ & $\Gamma$ \\
\hline
\end{tabular}

Other (please specify)

16. Describe any sustainable or pono fishing practices that you practice.

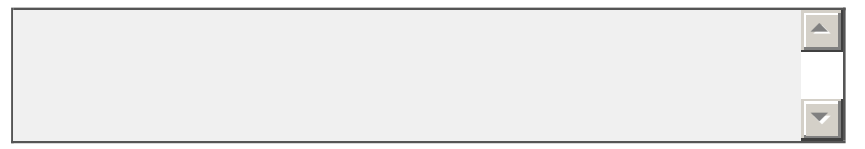

